\title{
Synthesis and Testing of Zeolite from Industrial- Waste Coal Fly Ash as Sorbent For Water Adsorption from Ethanol Solution
}

\author{
Panu Panitchakarn ${ }^{1}$, Thepparat Klamrassamee ${ }^{2}$, Navadol Laosiripojana ${ }^{2}$, \\ Nawin Viriya-empikul ${ }^{3}$, and Prasert Pavasant ${ }^{1} *$ \\ 1 Department of Chemical Engineering, Faculty of Engineering, Chulalongkorn University, Bangkok 10330, \\ Thailand \\ 2 The Joint Graduate School of Energy and Environment, CHE Center for Energy Technology and \\ Environment, King Mongkut's University of Technology Thonburi, Bangkok 10140, Thailand \\ 3 National Nanotechnology Center, National Science and Technology Development Agency, Pathum Thani \\ 12120, Thailand \\ *E-mail: presert.p@chula.ac.th
}

\begin{abstract}
In the present work, zeolite was prepared from industrial-waste coal fired ash (CFA) by fusion technique with and without acid-washing pretreatment under various conditions. The synthesized materials were then tested for water adsorption from bioethanol solution with an aim to produce a high purity ethanol $(>99.5 \%)$ for later utilization in gasohol production manufacturing. From our studies, it was found that the impurities (i.e., $\mathrm{Fe}_{2} \mathrm{O}_{3}, \mathrm{TiO}_{2}, \mathrm{MgO}, \mathrm{CaO}, \mathrm{K}_{2} \mathrm{O}$ and $\mathrm{SO}_{3}$ ) in $\mathrm{CFA}$ could be efficiently removed by acid-washing pretreatment. Among three different acids studied (i.e. HCl, $\mathrm{HNO}_{3}$, and $\mathrm{H}_{2} \mathrm{SO}_{4}$ ), $\mathrm{HCl}$ exhibited the highest pretreatment performance, while the most suitable pretreatment conditions to enhance high purity raw material (up to $85 \%$ purity) were by using $20 \% \mathrm{HCl}$ with the acid to $\mathrm{CFA}$ ratio of $25 \mathrm{ml}_{\mathrm{HCl}} / \mathrm{g}_{\mathrm{CFA}}$ at $80^{\circ} \mathrm{C}$ for $3 \mathrm{~h}$. After fusion at $550^{\circ} \mathrm{C}$ with $\mathrm{NaOH} / \mathrm{CFA}$ mass ratio of 2.25 and further crystallization at $90^{\circ} \mathrm{C}$ for $4 \mathrm{~h}$, the pretreated CFA was converted to zeolite; from which the main phases were sodium aluminum silicate hydrate $\left(1.08 \mathrm{Na}_{2} \mathrm{O} \bullet \mathrm{Al}_{2} \mathrm{O}_{3} \bullet 1.68 \mathrm{SiO}_{2} \bullet 1.8 \mathrm{H}_{2} \mathrm{O}\right)$ and faujasite- $\mathrm{Na}$ $\left(\mathrm{Na}_{2} \mathrm{Al}_{2} \mathrm{Si}_{2.4} \mathrm{O}_{8.8^{\bullet}} 6.7 \mathrm{H}_{2} \mathrm{O}\right)$. Regarding water adsorption testing, the synthesized zeolite provided comparable adsorption performance with the commercial grade molecular sieve. Under three adsorption cycles testing at $85^{\circ} \mathrm{C}$, high ethanol purity $(99.8 \%)$ could be achieved without deactivation being observed.
\end{abstract}

Keywords: Zeolite, coal fly ash, fusion, water adsorption, bioethanol.

ENGINEERING JOURNAL Volume 18 Issue 1

Received 8 January 2013

Accepted 18 April 2013

Published 14 January 2014

Online at http://www.engj.org/

DOI:10.4186/ej.2014.18.1.1 


\section{Introduction}

To date, the energy crisis due to the shortage and the price rise of gasoline in the transportation sector is one of the world's most pressing concerns. Bioethanol is known as a promising alternative fuel that can partially replace gasoline, namely gasohol. Generally, ethanol can be efficiently produced from the digestion and/or fermentation of starch and sugar. These processes typically produce ethanol with approximately $30 \%$ concentration (by volume). Importantly, this ethanol solution must be concentrated by distillation and dehydration to high purity ethanol $(99.5 \%)$ prior to mixing it with gasoline. The current commercial technology to purify ethanol consists of two main processes; the first process is by passing ethanol solution through the distillation system to increase the concentration of ethanol to $95 \%$; then the second process is to dehydrate the remaining water in ethanol solution by adsorption to enhance the ethanol concentration to $99.5 \%$. Regarding the adsorption process, zeolite molecular sieve is practically applied economically [1].

Coal fly ash (CFA) is an important by-product from the combustion of coal in power generation; it was reported that Thailand regularly generates more than 5.1 million tons of CFA per year, with a tendency to increase every year [2]. The management of CFA therefore becomes both an economic and an environmental issue. In this study, we aimed to use industrial-waste CFA as a raw material to synthesize zeolite since the typical components of CFA are amorphous aluminosilicate glasses, which are the main raw material for zeolite manufacturing [3]. Theoretically, zeolite are crystalline aluminum-silicates, with group I or II elements as counterions. Their structure is made up of a framework of $\left[\mathrm{SiO}_{4}\right]^{4-}$ and $\left[\mathrm{AlO}_{4}\right]^{5-}$ tetrahedra linked to one another at the corners by sharing their oxygen. The tetrahedra make up a three-dimensional network with lots of voids and open spaces; these voids result in several special properties of zeolite e.g., high thermal stability, ion exchange capability, liquid and gas adsorption capability and selective catalytic behavior. Zeolite can be classified into two groups that is natural and synthesized zeolite. Usually, synthesized zeolite are preferable to the natural zeolite due to the flexibility of pore size adjustment through different synthesizing techniques. It is known that about 24 types of zeolite can be synthesized; among them, zeolite A and faujasite are known as the most valuable forms. Particularly, faujasite-type zeolite is widely applied in several petrochemical industries since the dealuminated form of faujasite enables catalytic activities for various reactions due to their high acid properties, while the cationic form of faujasite can be efficiently applied for gas recuperation and/or separation owing to their selective adsorption properties. Importantly, it is known that cationic forms of zeolite present a strong water adsorption capacity when exchanging with some cations that is (i.e. $\mathrm{Na}^{+}, \mathrm{Li}^{+}, \mathrm{K}^{+}, \mathrm{Mg}^{2+}$ or $\left.\mathrm{Ca}^{2+}\right)[4,5,6]$; nevertheless, the reports relevant to water adsorption properties of faujasite remain limited.

Regarding the zeolite synthesis process, there are currently two potential methods including hydrothermal and fusion methods $[5,7]$. The fusion method gains advantages in terms of the short time requirement [5] and the achievement of high purity product $[8,9]$, whereas the hydrothermal method enhances benefits in terms of the consistent pattern of zeolite product. Generally, it is known that the fusion method is preferable for the solid-phase reaction, while the hydrothermal method is more appropriate for the reaction in liquid phase. Hence, the fusion method is considered as the appropriate technique for solid CFA conversion. Molina and Poole [10] compared the fusion with the hydrothermal methods for producing zeolite from UK fly ash; the researchers indicated that relatively higher zeolite $\mathrm{X}$ is synthesized from the fusion method; furthermore, the use of hydrothermal method results in the presences of crystalline phases (i.e., quartz and mullite) in the products. Importantly, for the fusion method, several researchers $[8,10,11-13]$ have agreed that the preparation conditions, that is $\mathrm{NaOH} / \mathrm{fly}$ ash ratio, reaction time and temperature, showed a significant impact on the type and the properties of zeolite achieved; therefore the conditions must be carefully controlled.

This work evaluated the suitable conditions in the conversion of the industrial waste CFA to zeolite molecular sieve by fusion method using $\mathrm{NaOH}$ as the activation reagent. Various preparation conditions including $\mathrm{NaOH} / \mathrm{CFA}$ ratio and reaction temperature were carried out in order to determine the suitable fusion conditions. Importantly, due to the presence of high impurities in raw CFA, the acid-washing pretreatment was performed prior to the fusion process since it has been reported that this pretreatment method could efficiently remove several mineral compounds from CFA [14]. It has been noted that the acid-washing pretreatment was carried out with various acid types (i.e., $\mathrm{HCl}, \mathrm{H}_{2} \mathrm{SO}_{4}$, and $\mathrm{HNO}_{3}$ ), acid concentrations, acid/CFA ratios, pretreatment temperatures and times with an aim to optimize the suitable pretreatment conditions for removing impurities from CFA. After preparation, the synthesized zeolites 
were then tested as sorbent for water adsorption from ethanol solution. Its adsorption capacity was also compared to the commercial grade molecular sieve.

\section{Experimental}

\subsection{Raw Material}

CFA was obtained from a coal fired thermal power system of a local pulp manufacturer in Thailand. The chemical compositions of the CFA sample were analyzed by X-ray fluorescence (XRF) (Philips, model PW2400 the Netherlands) as shown in Table 1.

\subsection{Acid-Washing Pretreatment Procedure}

The acid-washing pretreatment of CFA was carried out under various pretreatment conditions (i.e. different acid type, acid concentration, acid/CFA ratio, pretreatment temperature and time). In detail, $10 \mathrm{~g}$ of CFA was initially added to $\mathrm{HCl}, \mathrm{H}_{2} \mathrm{SO}_{4}$ and $\mathrm{HNO}_{3}$ solutions (with $10 \%, 20 \%$ and $30 \%$ acid concentrations) with the acid/CFA ratios of $25 \mathrm{ml}_{\mathrm{HCl}} \mathrm{g}_{\mathrm{CFA}^{-1}}, 30 \mathrm{ml}_{\mathrm{HCl}} \mathrm{g}_{\mathrm{CFA}^{-1}}$ and $40 \mathrm{ml}_{\mathrm{HCl}} \mathrm{g}_{\mathrm{CFA}^{-1}}$. The mixture was stirred constantly at a rate of $300 \mathrm{rpm}$ at three different temperatures $\left(70^{\circ} \mathrm{C}, 80^{\circ} \mathrm{C}\right.$ and $\left.90^{\circ} \mathrm{C}\right)$ for $1 \mathrm{~h}, 2 \mathrm{~h}$, and $3 \mathrm{~h}$. Next, the solid sample was filtered off from the solution and washed repeatedly with distilled water until the solution reached $\mathrm{pH} 7$ before being dried overnight at $105^{\circ} \mathrm{C}$.

\subsection{Zeolite Synthesis by Fusion Method}

Zeolite was prepared by the fusion method following the procedures reported by Molina and Poole [10]. Firstly, $2 \mathrm{~g}$ of CFA (both pretreated and non-pretreated samples) was mixed with $\mathrm{NaOH}$ pellets (reagent grade) to obtain the $\mathrm{NaOH} / \mathrm{CFA}$ mass ratios of 1.2 and 2.25. The mixture was then fused under air flow $(100 \mathrm{ml} \mathrm{min}-1)$ at three different temperatures $\left(450^{\circ} \mathrm{C}, 550^{\circ} \mathrm{C}\right.$ and $\left.600^{\circ} \mathrm{C}\right)$ for $1 \mathrm{~h}$ in the tubular furnace. After cooling down, the product was crushed, mixed with $20 \mathrm{ml}$ or $40 \mathrm{ml}$ of distilled water, and put in the shaker at room temperature for $12 \mathrm{~h}$. The mixture was then sequentially crystallized under static condition of $90^{\circ} \mathrm{C}$ for $4 \mathrm{~h}$ where the crystal was collected through the filtration. The crystal was washed several times with distilled water (until the $\mathrm{pH}$ of the solution reached 7) and dried overnight at $105^{\circ} \mathrm{C}$.

Several physical characterizations of the solid products from the above preparation were observed using a variety of conventional techniques to determine the phase formation, the degree of crystalline, the material specific surface area and the pore size distribution. The X-ray diffraction (XRD) patterns of powder were determined by X-ray diffractometer, while BET surface area, cumulative pore volume and average pore diameter were measured by $\mathrm{N}_{2}$ physisorption technique using Micromeritics ASAP 2020 surface area and porosity analyzer.

\subsection{Water Adsorption Testing}

To undergo the water adsorption testing, an experimental reactor system was constructed. Ethanol solution ( $95 \%$ wt concentration) in vapor phase was fed through the system at the rate of $36 \mathrm{ml} \mathrm{h}^{-1}$ by a syringe pump passing through an evaporator, while the carrier gas (nitrogen) was controlled and introduced to the system by the mass flow controller. These inlet gaseous mixtures were introduced to the adsorption section, in which a $10-\mathrm{mm}$ diameter stainless steel reactor was mounted vertically inside the tubular furnace. The solid sample $(1 \mathrm{~g})$ was loaded into the stainless steel reactor over quartz wool to prevent the sample from moving out of the adsorption zone. In the system, a Type-K thermocouple was placed into the annular space between the reactor and the furnace. This thermocouple was mounted in close contact with the sample bed to minimize the temperature difference. The adsorption temperatures studied in this work were varied from $85^{\circ} \mathrm{C}$ to $100^{\circ} \mathrm{C}$.

After the adsorption, the exit mixture gas was transferred to the cooling bath system (controlling the temperature at $10^{\circ} \mathrm{C}$ ) for condensing ethanol solution in the product line. The liquid product was collected from the cooling bath every 3 min and was analyzed by Karl Fischer titrator (KF, model 870 Titrino plus) in order to measure the water concentration. The reusability of solid sample was also tested by treating the 
spent sample under nitrogen flow at $280^{\circ} \mathrm{C}$ for $3 \mathrm{~h}$ before re-packing in the reactor for a repeating water adsorption test.

\section{Results and Discussion}

\subsection{Pretreatment of CFA by Acid-Washing}

Table 1 presents the composition of CFA after acid-washing treatment with $\mathrm{HCl}, \mathrm{H}_{2} \mathrm{SO}_{4}$, and $\mathrm{HNO}_{3}$ (at the acid concentrations of $10 \%, 20 \%$ and $30 \%$ ). Treatment with these acids enables the removal of impurities (i.e., $\mathrm{Fe}_{2} \mathrm{O}_{3}, \mathrm{TiO}_{2}, \mathrm{MgO}, \mathrm{CaO}, \mathrm{K}_{2} \mathrm{O}$ and $\mathrm{SO}_{3}$ ) in $\mathrm{CFA}$ resulting in the presence of higher $\mathrm{SiO}_{2}$ and $\mathrm{Al}_{2} \mathrm{O}_{3}$ percentages in the product. Among these three acids, the treatment with $\mathrm{HCl}$ provides the highest purity raw material (78-85\% of $\mathrm{SiO}_{2}$ and $\mathrm{Al}_{2} \mathrm{O}_{3}$ depending on the acid concentration), whereas treatment with $\mathrm{HNO}_{3}$ achieves the lowest purity (60-70\%). Notably, treatment with $\mathrm{H}_{2} \mathrm{SO}_{4}$ and $\mathrm{HNO}_{3}$ effectively remove $\mathrm{CaO}$ from CFA but are ineffective for $\mathrm{Fe}_{2} \mathrm{O}_{3}$ removal. On the other hand, the treatment with $\mathrm{HCl}$ efficiently removes both $\mathrm{CaO}$ and $\mathrm{Fe}_{2} \mathrm{O}_{3}$ from CFA. From the results, there were no significant changes in the percent yield of CFA after treatment with three acids $\left(\mathrm{HCl}, \mathrm{H}_{2} \mathrm{SO}_{4}, \mathrm{HNO}_{3}\right)$, they were all in a range of 54--57\%wt. Regarding the effect of acid concentration, it can be seen from Table 1 that the product purity strongly increases with increasing acid concentration from $10 \%$ to $20 \%$; nevertheless, this positive effect becomes less pronounced when the acid concentration increases to $30 \%$. Hence, it is observed from this study that $\mathrm{HCl}$ with a $20 \%$ concentration is the most suitable for CFA pretreatment.

Next, the effects of acid/CFA ratio, treatment temperature, and treatment time on the product purity from the acid-washing pretreatment with $\mathrm{HCl}$ were further examined. The acid/CFA ratio shows insignificant impact on the product purity, whereas the increasing treatment temperature from 60 to 70 and $80^{\circ} \mathrm{C}$ show a slightly positive effect on the product purity, but this positive impact became an inhibitory impact at $90^{\circ} \mathrm{C}$ (Fig. 1). From the XRF analysis, the $\mathrm{Fe}_{2} \mathrm{O}_{3}$ content in $\mathrm{CFA}$ reduces from $17.3 \%$ to $16.4 \%$ and $13.2 \%$ when the treatment temperature increases from $60^{\circ} \mathrm{C}$ to $70^{\circ} \mathrm{C}$ and $80^{\circ} \mathrm{C}$, which could be due to the increase of reaction rate between $\mathrm{HCl}$ and $\mathrm{Fe}_{2} \mathrm{O}_{3}$ with increasing temperature; nevertheless, at $90^{\circ} \mathrm{C}$ $\mathrm{Fe}_{2} \mathrm{O}_{3}$ content increased to $19.1 \%$ indicating a lower reaction rate between both compounds at this high temperature. This result corresponds to the findings of Wang et al. [14] who also reported the optimum temperature for acid-washing pretreatment of fly ash at $80^{\circ} \mathrm{C}$. Lastly, the effect of pretreatment time on the product purity was carried out by varying the pretreatment time from $1 \mathrm{~h}$ to $2 \mathrm{~h}$ and $3 \mathrm{~h}$. Also shown in Fig. 1 , the product purity increased with an increasing pretreatment time from $1 \mathrm{~h}$ to $2 \mathrm{~h}$ and continues to increase slightly at $3 \mathrm{~h}$. According to the XRF analysis, the change in product purity with pretreatment time mainly relates to the presence of $\mathrm{Fe}_{2} \mathrm{O}_{3}$ at different pretreatment times (the content of this impurity compound decreases from $17.6 \%$ to $13.8 \%$ and $12.8 \%$ at the pretreatment time of $1 \mathrm{~h}, 2 \mathrm{~h}$ and $3 \mathrm{~h}$, respectively). Based on these results, the optimum conditions for acid-washing pretreatment are a $20 \% \mathrm{HCl}$ with $\mathrm{HCl} / \mathrm{CFA}$ ratio of 25 at $80^{\circ} \mathrm{C}$ for $3 \mathrm{~h}$.

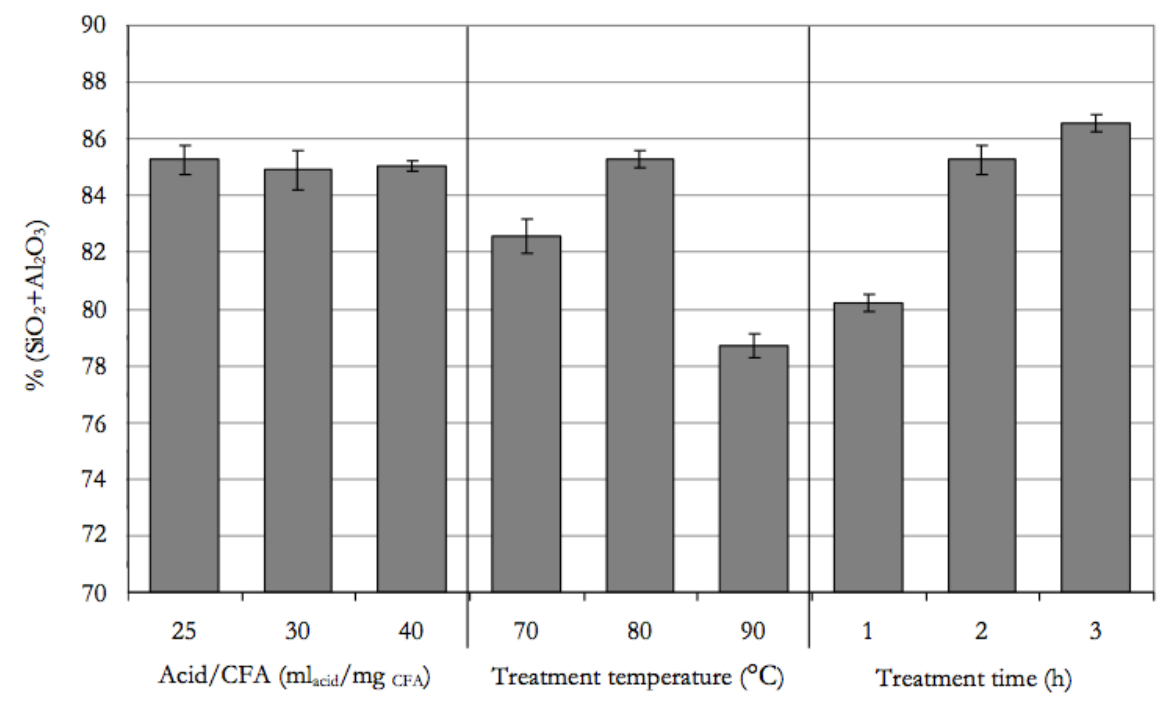

Fig. 1. Effects of acid/CFA ratio, treatment temperature, and treatment time on product purity from the acid-washing pretreatment with $\mathrm{HCl}(20 \%$ concentration). 


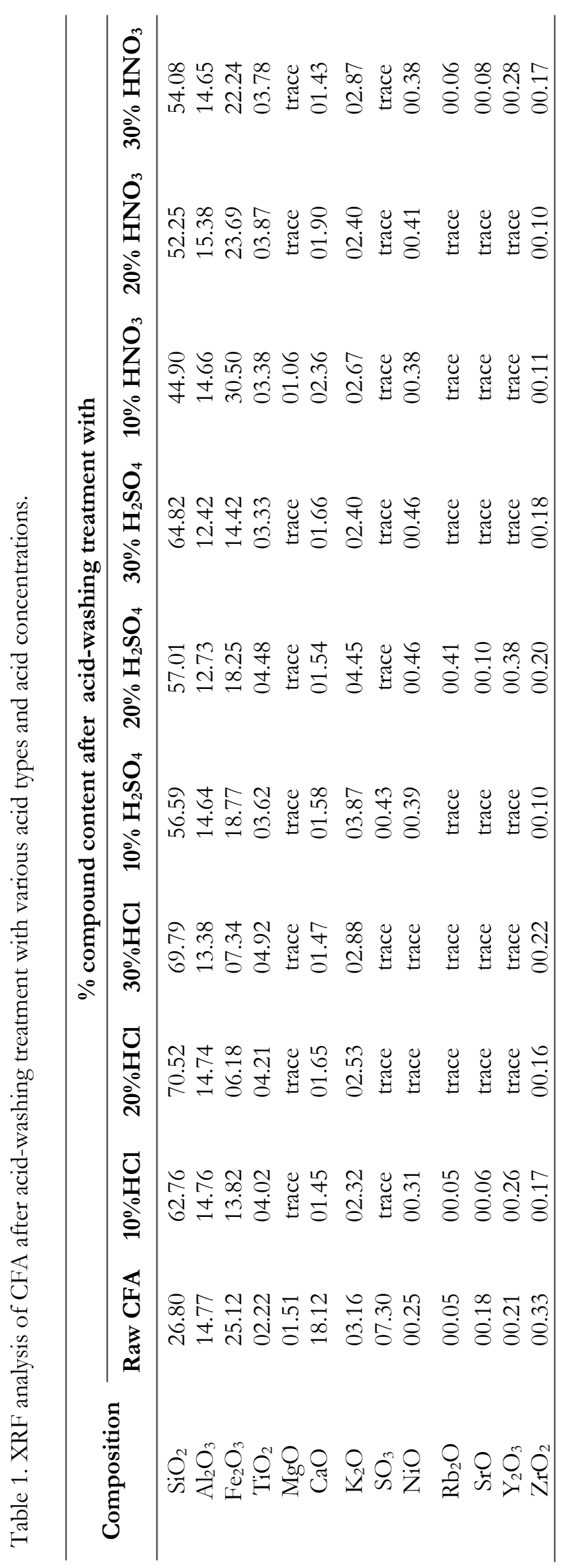




\subsection{Zeolite Synthesis from Treated and Untreated CFA}

The fusion method was carried out on pretreated and non-pretreated CFA samples using the fusion temperature of $450^{\circ} \mathrm{C}$ with $\mathrm{NaOH} / \mathrm{CFA}$ ratio of 2.25 for $12 \mathrm{~h}$ followed by crystallization at $90^{\circ} \mathrm{C}$ for $4 \mathrm{~h}$. $\mathrm{XRD}$ results suggest that the main phase formation of zeolite synthesized from non-pretreated CFA is sodium aluminum silicate hydrate $\left(1.08 \mathrm{Na}_{2} \mathrm{O} \bullet \mathrm{Al}_{2} \mathrm{O}_{3} \bullet 1.68 \mathrm{SiO}_{2} \bullet 1.8 \mathrm{H}_{2} \mathrm{O}\right.$, JCDPS number 00-031-1271), whereas the phase formation of zeolite synthesized from the pretreated CFA contains both sodium aluminum silicate hydrate and $\mathrm{Na}$-Faujasite $\left(\mathrm{Na}_{2} \mathrm{Al}_{2} \mathrm{Si}_{2.4} \mathrm{O}_{8.8} \cdot 6.7 \mathrm{H}_{2} \mathrm{O}\right.$, JCDPS number 12-0246) as shown in Fig. 2. Furthermore, BET results as demonstrated in Table 2 show that the pretreated sample has higher specific surface area and total pore volume with smaller pore size diameter.

To investigate the effect of fusion temperature, experiments with various $\mathrm{NaOH} / \mathrm{CFA}$ ratios (from 2.25 to 1.2 ) and crystallization condition (with $20 \mathrm{ml}$ and $40 \mathrm{ml}$ of adding water prior to crystallization) were carried out at various fusion temperatures $\left(450^{\circ} \mathrm{C}, 550^{\circ} \mathrm{C}\right.$ and $\left.600^{\circ} \mathrm{C}\right)$. Previously, several researchers reported different suitable fusion temperatures. Rayalu et al. [9] and Sommerset et al. [15] suggested the optimum fusion temperature of $600^{\circ} \mathrm{C}$, whereas Molina and Poole [10], Ojha et al. [16] and Shigemoto et al. [17] reported the optimum fusion temperature of $550^{\circ} \mathrm{C}$. In this study it was determined that the fusion temperature provides insignificant impact on the material phase formation (Fig. 3) but strongly affects the material specific surface area and pore diameter, particularly for the pretreated samples. As shown in Table 2, the specific surface area of pretreated CFA increases from 151.7 to $227 \mathrm{~m}^{2} \mathrm{~g}^{-1}$ as the fusion temperature increases from $450^{\circ} \mathrm{C}$ to $550^{\circ} \mathrm{C}$; nevertheless, at the fusion temperature of $600^{\circ} \mathrm{C}$, the specific surface area remains constant (or slightly decreases) at $223 \mathrm{~m}^{2} \mathrm{~g}^{-1}$.

Table 2. BET measurement of product after fusion at various temperatures.

\begin{tabular}{lccccc}
\hline \multicolumn{1}{c}{ Sample } & $\begin{array}{c}\text { Acid-washing } \\
\text { Pretreatment }\end{array}$ & $\begin{array}{c}\text { Fusion } \\
\text { Temp. } \\
\left({ }^{\circ} \mathbf{C}\right)\end{array}$ & $\begin{array}{c}\text { Surface } \\
\text { Area } \\
\left(\mathbf{m}^{2} / \mathbf{g}\right)\end{array}$ & $\begin{array}{c}\text { Pore } \\
\text { Diameter } \\
(\mathbf{n m})\end{array}$ & $\begin{array}{c}\text { Pore } \\
\text { Volume } \\
\left(\mathbf{c m}^{3} / \mathbf{g}\right)\end{array}$ \\
\hline HCl-F450-Na2.25-C20 & without & 450 & 58.3 & 19.5 & 0.28 \\
HCl-F550-Na2.25-C20 & with & 550 & 49.4 & 21.36 & 0.26 \\
HCl-F600-Na2.25-C20 & with & 600 & 69.14 & 19.16 & 0.33 \\
Z-HCl-F450-Na2.25-C20 & with & 450 & 151.7 & 13.7 & 0.52 \\
Z-HCl-F550-Na2.25-C20 & with & 550 & 227.0 & 9.94 & 0.56 \\
Z-HCl-F600-Na2.25-C20 & with & 600 & 223.1 & 11.6 & 0.54 \\
Z-HCl-F450-Na1.20-C20 & with & 450 & 223.3 & 7.69 & 0.45 \\
Z-HCl-F550-Na2.25-C40 & with & 550 & 72.8 & 22.5 & 0.41 \\
\hline
\end{tabular}




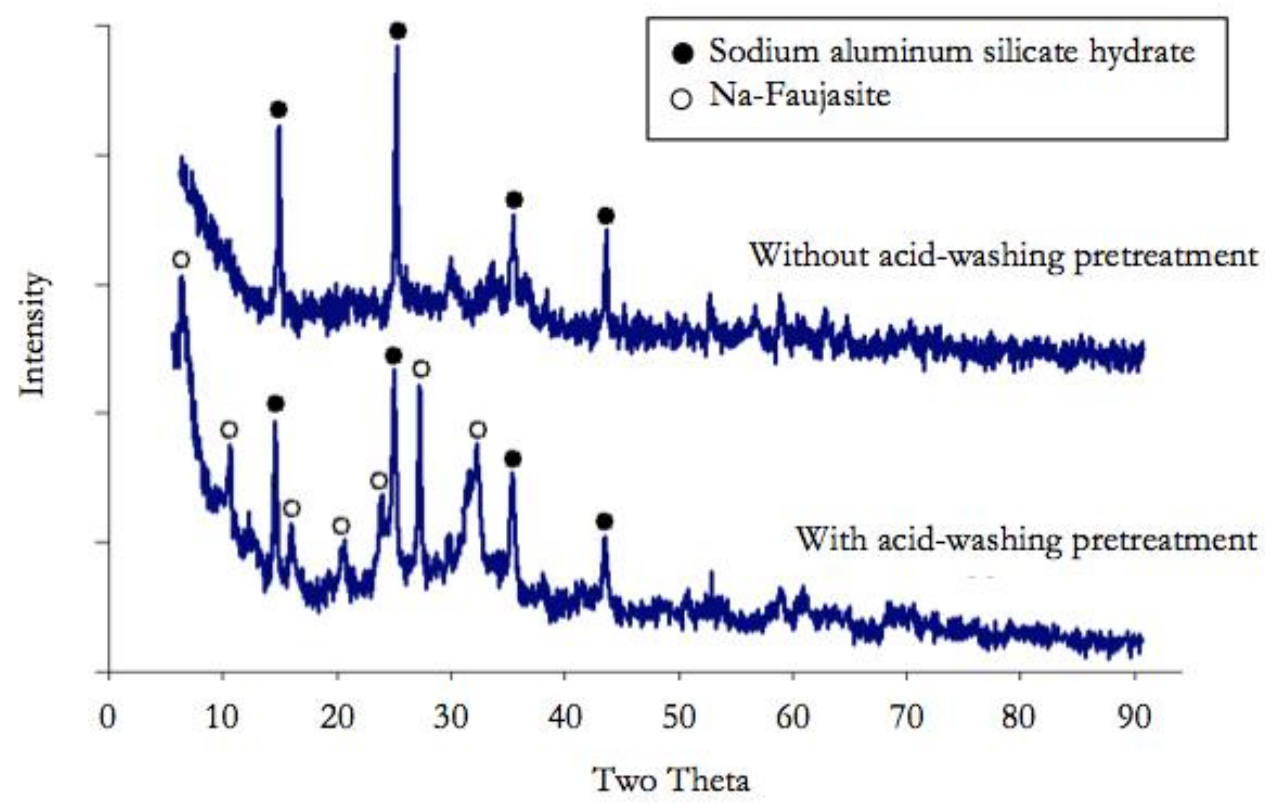

Fig. 2. Phase formations of pretreated and non-pretreated CFA samples after fusion process (fusion temperature of $450^{\circ} \mathrm{C}$ with $\mathrm{NaOH} / \mathrm{CFA}$ ratio of 2.25 for $12 \mathrm{~h}$ following with crystallization at $90^{\circ} \mathrm{C}$ for $4 \mathrm{~h}$ ).

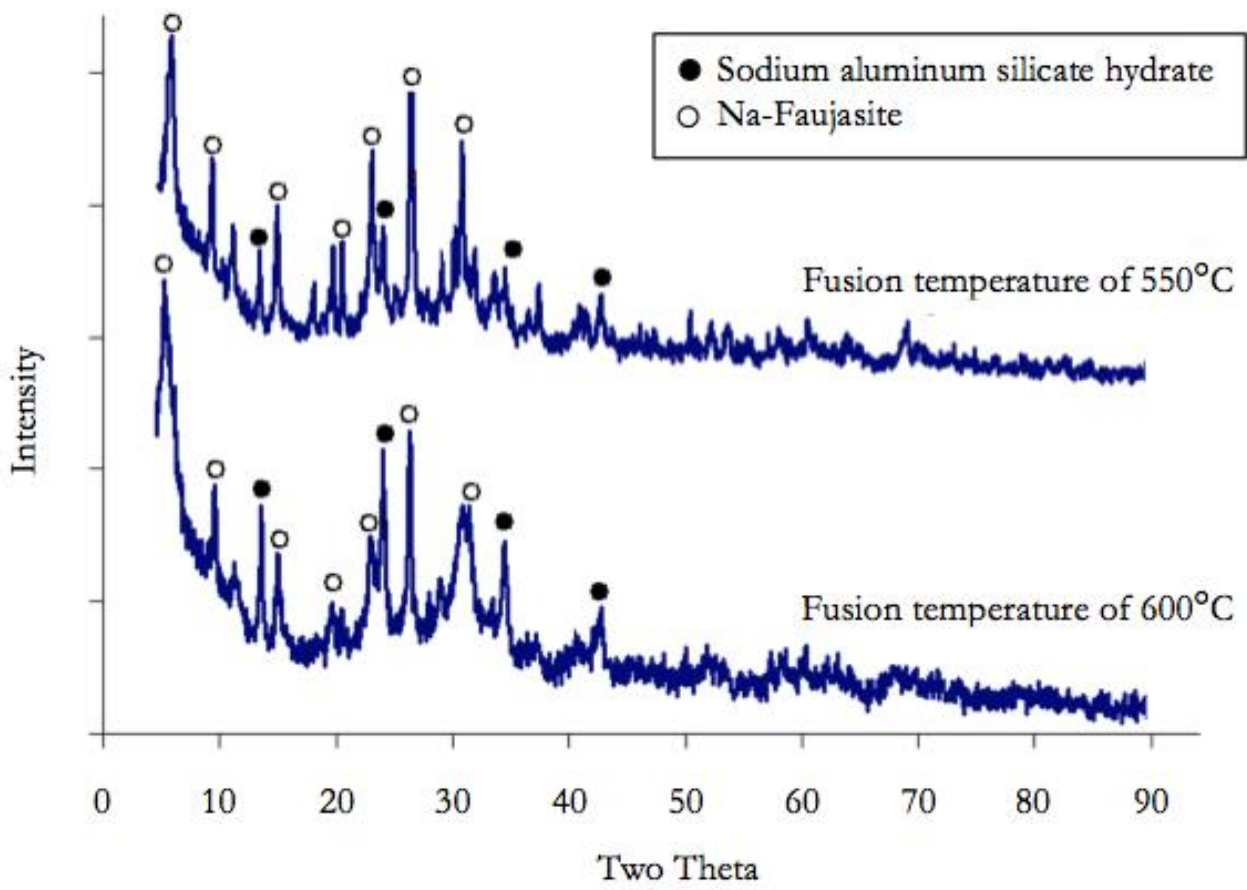

Fig. 3. Phase formations of samples after fusion at different temperatures (using $\mathrm{NaOH} / \mathrm{CFA}$ ratio of 2.25 for $12 \mathrm{~h}$ following with crystallization at $90^{\circ} \mathrm{C}$ for $4 \mathrm{~h}$ ).

Presently, there have only been a few studies related to the effect of $\mathrm{NaOH} / \mathrm{CFA}$ ratio during the fusion process on the product formation. For instance, Rayalu et al. [9], Carlos et al. [18] and Molina and Poole [10] reported that the use of $\mathrm{NaOH} / \mathrm{CFA}$ ratio of 1.2 (under the fusion temperature of $600^{\circ} \mathrm{C}$, and crystallization temperature of $105^{\circ} \mathrm{C}$ for $24 \mathrm{~h}$ ) provided an almost $100 \%$ purity faujasite product; whereas Molina and Poole [10] suggested the suitable $\mathrm{NaOH} / \mathrm{CFA}$ ratio of 2.25. We found insignificant effect of $\mathrm{NaOH} / \mathrm{CFA}$ ratio on the phase formation and specific surface area of material (the specific surface area 
changes from $227 \mathrm{~m}^{2} \mathrm{~g}^{-1}$ at $\mathrm{NaOH} / \mathrm{CFA}$ ratio of 2.25 to $232 \mathrm{~m}^{2} \mathrm{~g}^{-1}$ at $\mathrm{NaOH} / \mathrm{CFA}$ ratio of 1.2). Lastly, regarding the effect of crystallization condition, it was observed that the amount of water used during the crystallization period strongly affects the phase formation of the product. By increasing the amount of water from $20 \mathrm{ml}$ to $40 \mathrm{ml}$, the phase of product became only sodium aluminum silicate hydrate, as shown in Fig. 4. This could be due to the fact that water is one major component in zeolite structure having the empirical formula of $\mathrm{M}_{2 / \mathrm{n}} \mathrm{O} \cdot \mathrm{Al}_{2} \mathrm{O}_{3} \cdot \mathrm{ySiO}_{2} \cdot \mathrm{wH}_{2} \mathrm{O}$; hence, the use of different water amounts during the crystallization period lead to the change in zeolite structure. By using $40 \mathrm{ml}$ of water, the concentration of reactive species in the liquid phase is diluted, resulting in a decrease of the crystal growth rate, according to the relation: $\mathrm{Kg} \propto f(\mathrm{C})$; where $\mathrm{Kg}$ is the crystal growth and $\mathrm{C}$ is the concentration of sodium hydroxide [7]. Under this crystallization condition, it forms mainly sodium aluminum silicate hydrate.

\subsection{Performance of Synthesized Zeolite as Water Sorbent}

The water adsorption performances of synthesized zeolite products were investigated. Firstly, raw CFA with and without pretreatment were tested for water adsorption from ethanol solution at $90^{\circ} \mathrm{C}$. From the results, water could not be adsorbed by the treated and non-treated CFA. The zeolite samples were then prepared by acid washing pretreatment and fusion under different fusion temperatures are denoted as $Z$ $\mathrm{HCl}-\mathrm{F} 450, \mathrm{Z}-\mathrm{HCl}-\mathrm{F} 550$, and Z-HCl-F600 (which means zeolite prepared by $\mathrm{HCl}$ pretreatment and fusion at $450^{\circ} \mathrm{C}, 550^{\circ} \mathrm{C}$ and $600^{\circ} \mathrm{C}$ respectively). Furthermore, the samples prepared with different $\mathrm{NaOH} / \mathrm{CFA}$ and different amounts of water during the crystallization are denoted as Z-HCl-F450-Na1.2-C20 and ZHCl-F450-Na2.25-C20, which means zeolite prepared by fusion at $450^{\circ} \mathrm{C}$ with $\mathrm{NaOH} / \mathrm{CFA}$ ratio of 1.2 and 2.25 , respectively, prior to the crystallization with $20 \mathrm{ml}$ of water).

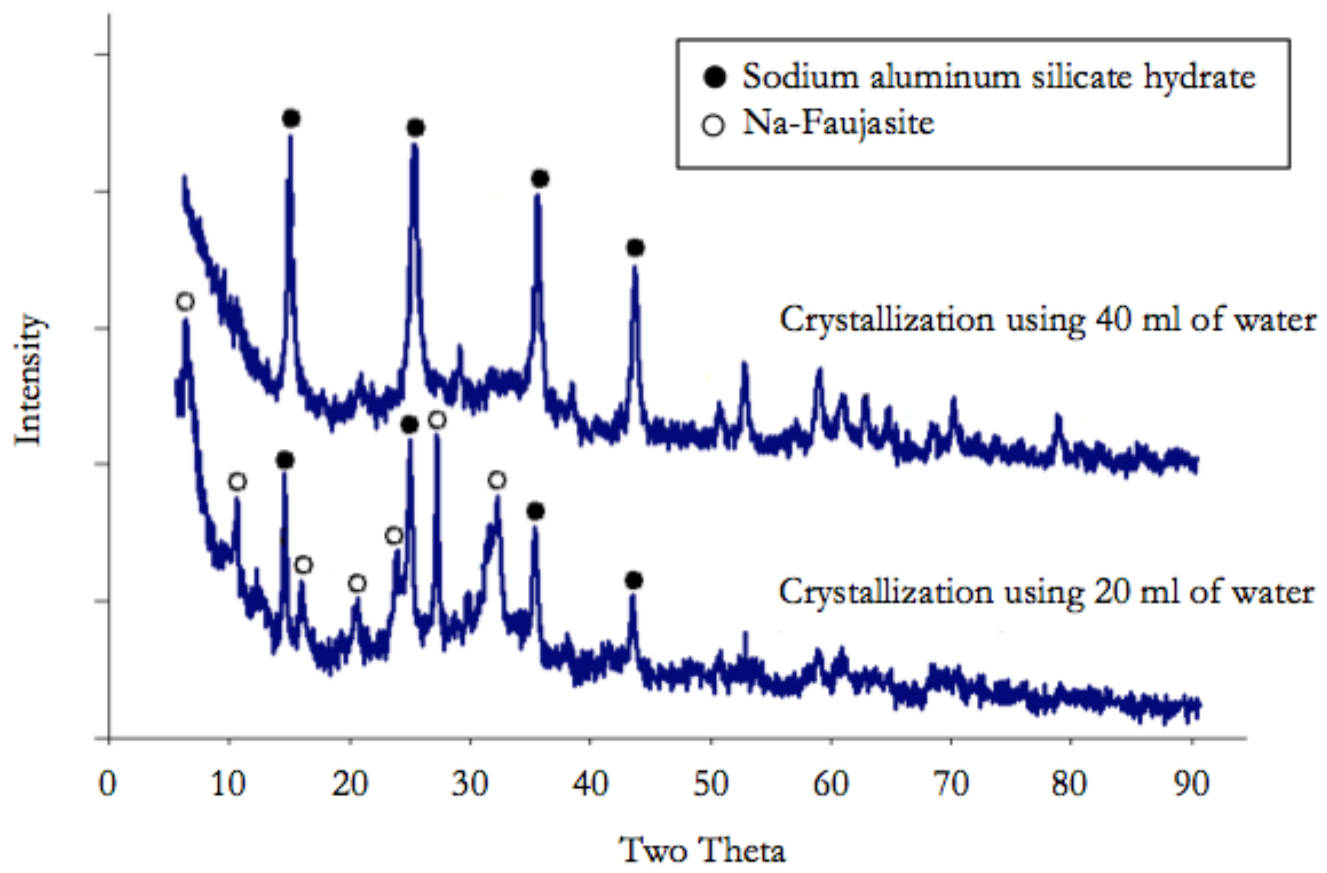

Fig. 4. Effect of water adding during crystallization on the phase formation of sample after fusion process (fusion temperature of $450^{\circ} \mathrm{C}$ with $\mathrm{NaOH} / \mathrm{CFA}$ ratio of 2.25 for $12 \mathrm{~h}$ following with crystallization at $90^{\circ} \mathrm{C}$ for $4 \mathrm{~h}$ ).

Figure 5 shows the breakthrough curve for water adsorption from ethanol solution at $90^{\circ} \mathrm{C}$ of all samples and was also compared to the commercial grade molecular-sieve (ZEOCHEM Z3-03 supplied from ZEOCHEM). The breakthrough curve is a plot of relative concentration $\left(C / C_{0}\right.$ ratio) versus time, where $C_{0}$ is the water concentration of the feed ethanol solution and $C$ is the water concentration of the outlet ethanol at a given time. From the results, the acid-washing pretreatment and fusion conditions (i.e. fusion temperature, $\mathrm{NaOH} / \mathrm{CFA}$ ratio and the amount of water used during crystallization) strongly affected the water adsorption capacity of material. The samples with acid-washing pretreatment prior to the 
fusion process demonstrated a greater adsorption capacity than the samples without acid-washing pretreatment. Among all synthesized samples, Z-HCl-F550-Na2.25-C20 shows the highest water adsorption capacity; its adsorption performance is comparable to the commercial grade molecular-sieve and reported adsorption values (molecular-sieve type 3A, 4A, 5A and biobased adsorbents) [19]. From the results, more than 99\%wt ethanol concentration could be achieved using Z-HCl-F550-Na2.25-C20 via the adsorption process (described in Section 2.4). Note that the reported adsorption capacities are in the range of 0.087-0.127 $\mathrm{g}_{\text {water }} \mathrm{g}_{\text {adsorbent }}{ }^{-1}[19]$ while Z-HCl-F550-Na2.25-C20 had an adsorption capacity of $0.158 \mathrm{~g}_{\text {water }}$ $\mathrm{g}_{\text {adsorbent }}{ }^{-1}$. This result clearly indicates the importance of material purity, phase formation and specific surface area on the water adsorption performance, in which the material with high purity, with the presence of Na-faujasite phase and with high specific surface area can gain high water adsorption performance. Currently, only a few studies have reported the water adsorption capability of $\mathrm{Na}$-faujasite. Generally, faujasite is known as cationic zeolite, which also presents a strong adsorption affinity for water. For most zeolites with a strong adsorption affinity for water, the adsorption is the result of specific interactions between water molecules and exchangeable cations, which are the hydrophilic sites. Moise et al. [4] explained that the water adsorption on faujasite occurred in three main steps, from which the first step corresponded to the adsorption on the hydrophilic sites with high absolute values of adsorption heats $(\approx 80$ $\mathrm{kJ} \mathrm{mol}^{-1}$ for $\mathrm{NaX}$ for sample) and the adsorption decreased sharply with an increase in water in the pore. The second step was attributed to the formation of monolayer on the walls of the supercages by hydrogen bonds between water molecule and oxygen atoms of zeolitic framework. For the third step, the saturation of cavities was reached and the adsorption heat decreased down to the vaporization heat of water. Hence, the water adsorption properties were strongly dependent on the nature and the density of exchangeable cations.

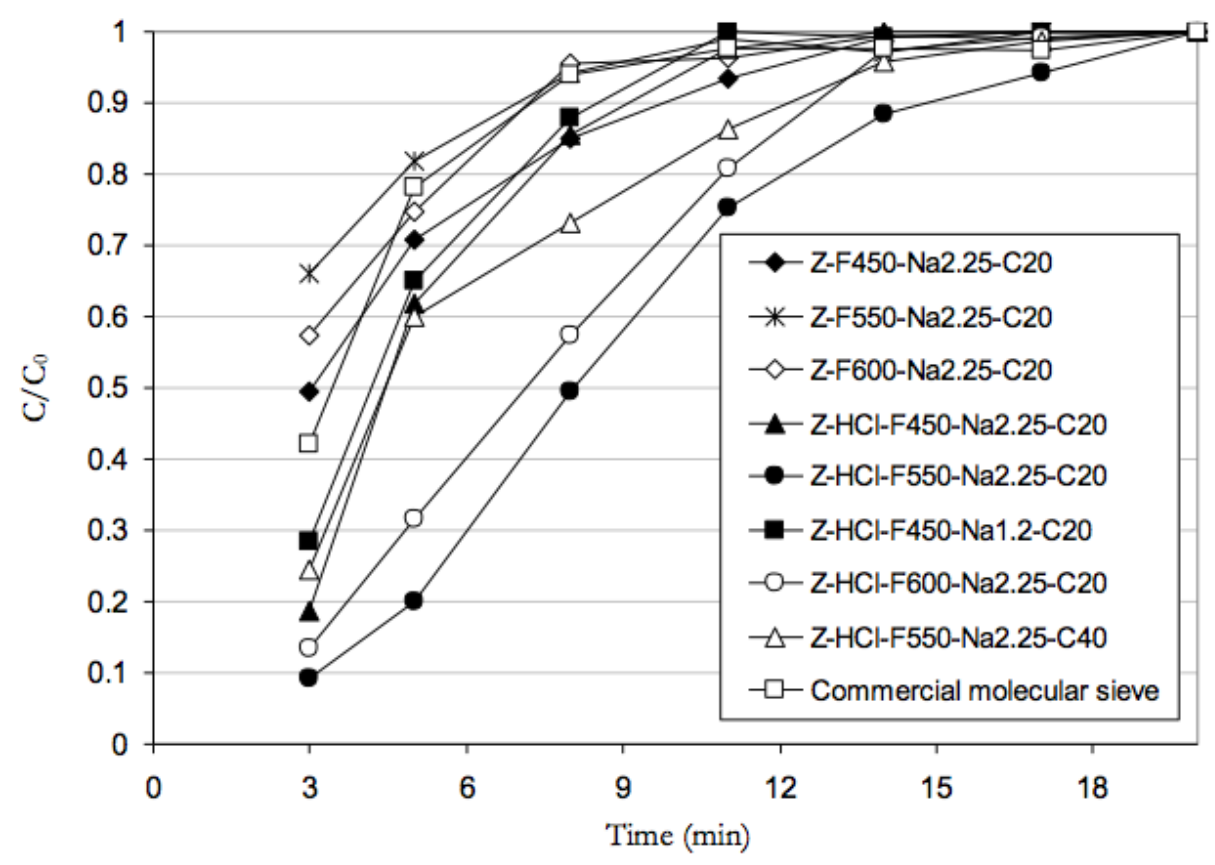

Fig. 5. Breakthrough curves of water adsorption using various sorbents (at adsorption temperature of $\left.90^{\circ} \mathrm{C}\right)$.

In addition to the phase formation, this study also indicated the strong effect of material specific surface area, pore volume and pore size on the water adsorption performance. The samples (with acidwashing pretreatment) having high specific surface area and pore volume can gain significantly better adsorption capacity than the samples without acid-washing pretreatment. Furthermore, the strong relation between the average pore diameter of material and the adsorption performance was also observed. The pretreated samples contain considerably lower average pore diameter compared with the untreated samples and present greater adsorption capacity; this could be due to the good compatibility between the pretreated material pore size and the diameter of water molecule $(2.8 \AA)$. These benefits on the phase formation, material specific surface area, the pore volume and the pore size clearly reveal the importance of 
pretreatment process on the sorbent synthesis. Lastly, it was observed that $\mathrm{NaOH} / \mathrm{CFA}$ ratio also affects the water adsorption performance. Z-HCl-F450-Na2.25-C20 contains higher amount of $\mathrm{Na}_{2} \mathrm{O}$ than Z-HClF450-Na1.2-C20 (21.1\% compared to 18.8\%, according to the XRF analysis) and enhances greater adsorption performance.

It should be noted that the effects of adsorption temperature and adsorption cycle on the water adsorption capacity were also investigated, from which Z-HCl-F550-Na2.25-C20 was chosen for these studies. The effects of adsorption temperature were performed by varying the adsorption temperature from $85^{\circ} \mathrm{C}$ to $90^{\circ} \mathrm{C}$ and $100^{\circ} \mathrm{C}$. It was found that the adsorption at $85^{\circ} \mathrm{C}$ enhances the highest water adsorption capability, from which the effluent ethanol concentration can increase to $99.8 \%$ compared $99 \%$ and $98.5 \%$ observed at $90^{\circ} \mathrm{C}$ and $100^{\circ} \mathrm{C}$, respectively, as shown in Fig. 6. Due to the exothermic characteristic of adsorption reaction, a low operation temperature is preferable; nevertheless, the operating temperature cannot be lower than $85^{\circ} \mathrm{C}$ since the vapor phase of ethanol solution could possibly be condensed. Regarding the effect of adsorption cycle, the sample was regenerated after the first cycle test (for 20 min) by purging hot nitrogen through the bed which increased the temperature to $280^{\circ} \mathrm{C}$ in order to remove all adsorbed water from the sample. Then, the system was cooled down to the adsorption temperature $\left(90^{\circ} \mathrm{C}\right)$ and the adsorption test was repeated for the second and third times without removing the sample from the bed. Figure 7 demonstrates that no deactivation occurred from the second and third cycle tests. In fact, the adsorption capacities of the second and third cycles seem to be slightly higher than that of the first cycle. This could be due to the regeneration under nitrogen flow at $280^{\circ} \mathrm{C}$ prior to the second and third time tests, from which all water in the material pore are efficiently removed (compared to the fresh sample with only drying treatment prior to the testing was performed).

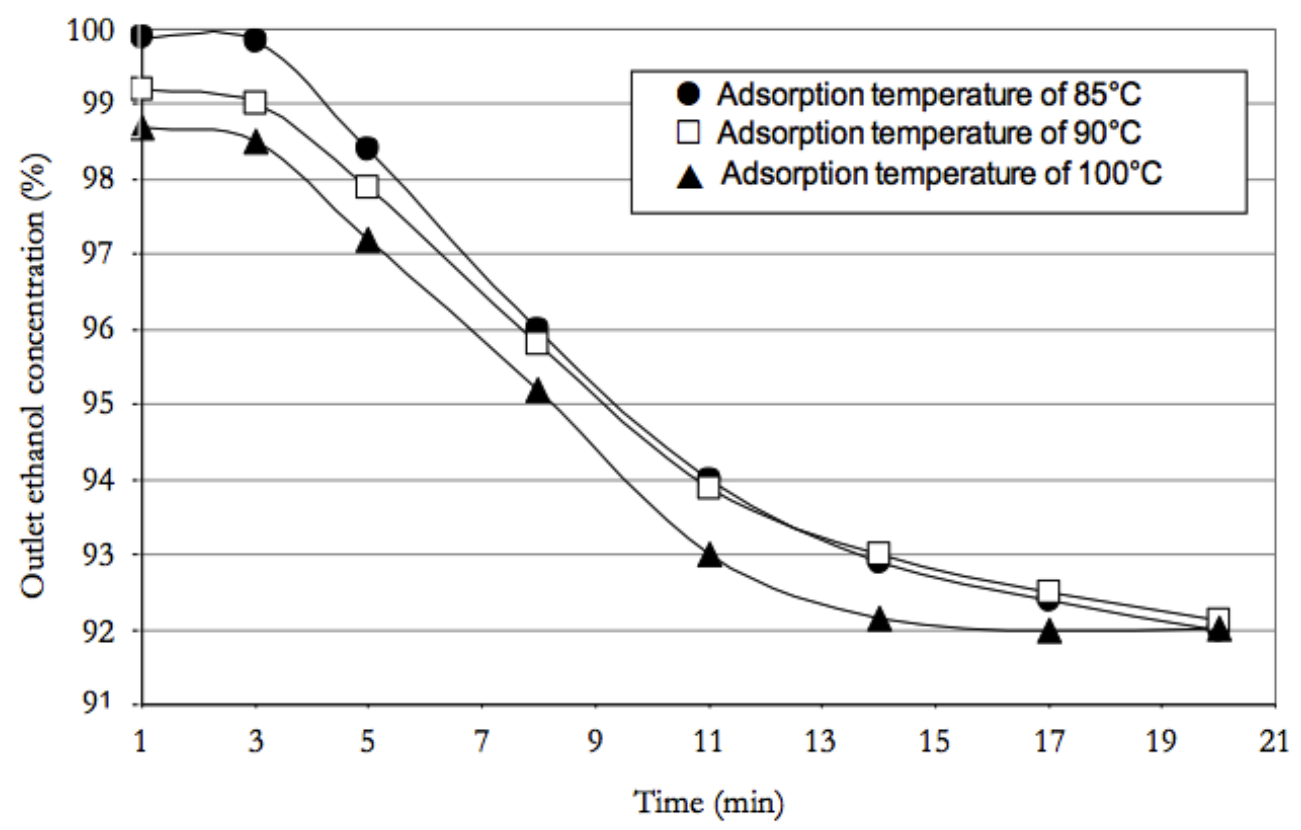

Fig. 6. Effect of adsorption temperature on the adsorption performance of Z-HCl-F550-Na2.25-C20. 


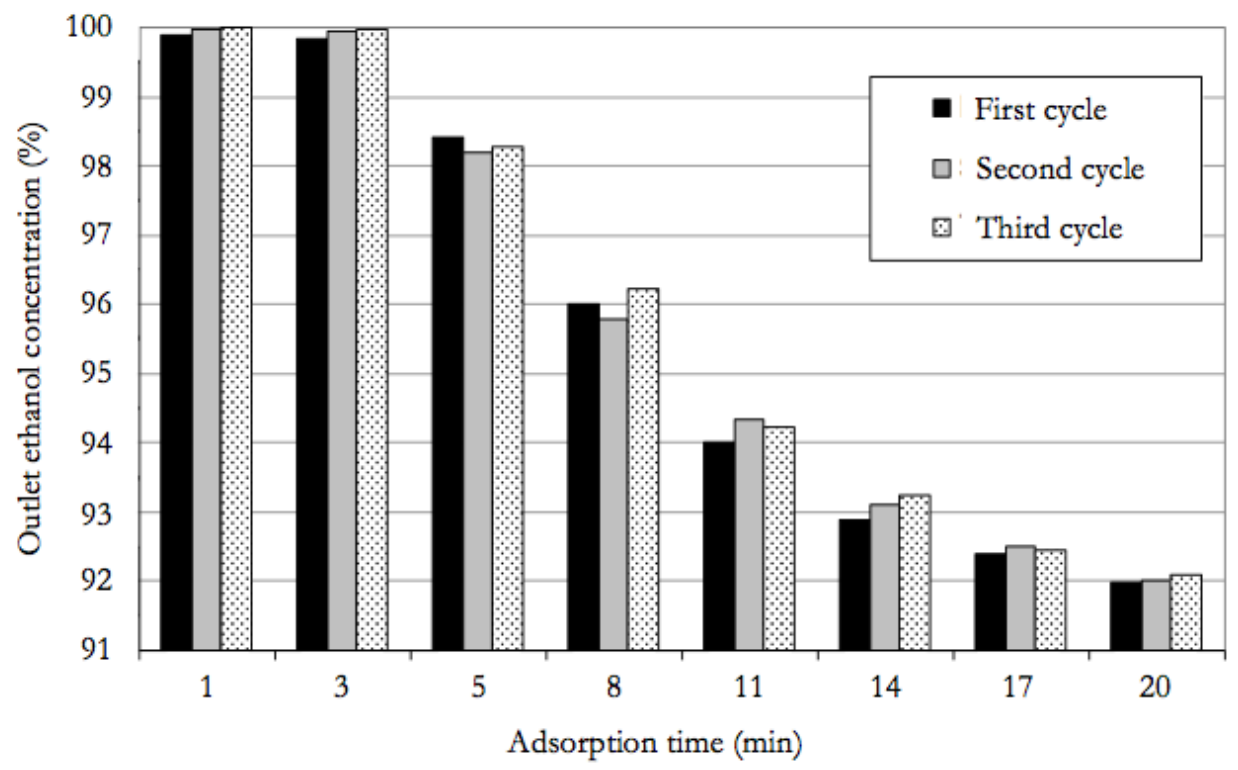

Fig. 7. Effect of adsorption cycle on the adsorption performance of Z-HCl-F550-Na2.25-C20 at $85^{\circ} \mathrm{C}$.

\section{Conclusions}

The acid-washing pretreatment with $20 \% \mathrm{HCl}$ using $\mathrm{HCl} / \mathrm{CFA}$ ratio of $25.0 \mathrm{ml}_{\mathrm{HCl}} / \mathrm{g}_{\mathrm{CFA}}$ at $80^{\circ} \mathrm{C}$ for $3 \mathrm{~h}$ could efficiently remove most impurities from CFA to trace levels (i.e., $\mathrm{CaO}$ and $\mathrm{MgO}$ ) and up to $85 \%$ purity of the product $\left(\mathrm{SiO}_{2}\right.$ and $\left.\mathrm{Al}_{2} \mathrm{O}_{3}\right)$ could be achieved. However, $\mathrm{Fe} 2 \mathrm{O} 3$ was reduced from $25.12 \%$ to $6.18 \%$. By further fusion at $550^{\circ} \mathrm{C}$ with $\mathrm{NaOH} / \mathrm{CFA}$ ratio of 2.25 for $12 \mathrm{~h}$ following with crystallization at $90^{\circ} \mathrm{C}$ for $4 \mathrm{~h}$, zeolite with the main phases of sodium aluminum silicate hydrate and faujasite-Na can be achieved. It was found that this synthesized material enhances good water adsorption performance comparable to commercial grade molecular sieve used to remove water from ethanol solution. At the adsorption temperature of $85^{\circ} \mathrm{C}, 99.8 \%$ ethanol purity can be achieved from the adsorption using this synthesized zeolite; furthermore, no significant deactivation was observed within the three adsorption cycles.

\section{Acknowledgements}

The financial support from The Thailand Research Fund (TRF) and Inter Pacific Paper Co. Ltd (Thailand) throughout this project is gratefully acknowledged.

\section{References}

[1] H. J. Huang, S. Ramaswamy, U. W. Tschirner, and B. V. Ramarao, "A review of separation technologies in current and future biorefineries," Separation and Purification Technology, vol. 62, pp. 1-21, 2008.

[2] Ministry of Energy, "Energy policy and planning of Thailand," Thailand, Annual Report, 2006.

[3] R. Kikuchi, "Application of coal ash to environmental improvement: Transformation into zeolite, potassium fertilizer, and FGD absorbent," Resources Conservation, and Recycling, vol. 27, pp. 333-346, 1999.

[4] J. C. Moise, J. P. Bellat, and A. Methivier, "Adsorption of water vapor on X and Y zeolites exchangeable with barium," Microporous and Mesoporous Materials, vol. 43, pp. 91-101, 2001.

[5] X. Querol, N. Moreno, J. C. Umana, A. Alastuey, E. Hernandez, A. Lopez-Soler, and F. Plana, "Synthesis of zeolite from coal fly ash: An overview," International Journal of Coal Geology, vol. 50, pp. 412-423, 2002.

[6] L. Li, J. Dong, and T. M. Nenoff, "Transport of water and alkali metal ions through MFI zeolite membranes during reverse osmosis," Separation and Purification Technology, vol. 53, pp. 42-48, 2007. 
[7] D. W. Breck, Zeolite Molecular Sieves. New York: John Wiley and Sons Inc., 1974.

[8] V. K. Jha, M. Nagae, M. Matsuda, and M. Miyake, "Zeolite formation from coal fly ash and heavy metal ion removal characteristics of thus-obtained zeolite $\mathrm{X}$ in multi-metal systems," Environmental Management, vol. 90, pp. 2507-2514, 2009.

[9] S. J. Rayalu, N. K. Udhoji, Z. M. Munshi, and J. Hasan, "Highly crystalline zeolite-A from fly ash of bituminous and lignite coal combustion," Journal of Hazard Materials, vol. 88, pp. 107-121, 2001.

[10] A. Molina and C. A. Poole, "Comparative study using two methods to produce zeolites from fly ash," Minerals Engineering, vol. 17, pp. 167-173, 2004.

[11] R. Apiratikul and P. Pavasant, "Sorption of $\mathrm{Cu}^{2+}, \mathrm{Cd}^{2+}$, and $\mathrm{Pb}^{2+}$ using modified zeolite from coal fly ash," Chemical Engineering Journal, vol. 144, pp. 245-258, 2008.

[12] R. Apiratikul and P. Pavasant, "Sorption isotherm model for binary component sorption of copper, cadmium, and lead ions using dried green macroalga, Caulerpa lentillifera," Chemical Engineering Journal, vol. 119, 135-145, 2006.

[13] T. Mishra and S. K. Tiwari, "Studies on sorption properties of zeolite derived from Indian fly ash," Journal of Hazardous Materials, vol. 137, pp. 299-303, 2006.

[14] C. F. Wang, J. S. Li, L. J. Wang, and X. Y. Sun, "Influence of $\mathrm{NaOH}$ concentrations on synthesis of pure-form zeolite A from fly ash using two-stage method," Journal of Hazardous Materials, vol. 55, pp. 58-64, 2008.

[15] V. S. Somerset, L. F. Petric, R. A. White, M. J. Kling, D. Key, and E. I. Iwuoha, "Alkaline hydrothermal zeolites synthesized from high $\mathrm{SiO}_{2}$ and $\mathrm{Al}_{2} \mathrm{O}_{3}$ co-disposal fly ash filtrates," Fuel, vol. 84 pp. 324-329, 2005.

[16] K. Ojha, N. C. Pradhan, and A. N. Samanta, "Kinetics of batch alkylation of phenol with tert-butyl alcohol over a catalyst synthesized from coal fly ash," Chemical Engineering Journal, vol. 112, pp. 109-115, 2005.

[17] N. Shigemoto and H. Hayashi, "Selective formation of Na-X zeolite from coal fly ash by fusion with sodium hydroxide prior to hydrothermal reaction," Journal of Materials Science, vol. 28, pp. 4781-4786, 1993.

[18] C. A. Rios, C. D. Williams, and C. L. Roberts, "A comparative study of two methods for the synthesis of fly ash-based sodium and potassium type zeolites," Fuel, vol. 88, pp. 1403-1416, 2009.

[19] S. Al-Asheh, F. Banat, and N. Al-Lagtah, "Separation of ethanol-water mixtures using molecular sieves and biobased adsorbent," Chemical Engineering Research and Design, vol. 82, pp. 855-864, 2004. 